\title{
Microstructure of Laser Welded-on Layers of 32CrMoV12-28 Steel with Maraging Alloy in Ageing
}

\author{
V. Shtarbakov ${ }^{\mathrm{a}}$, D. Stavrev ${ }^{\mathrm{b} *}$ \\ ${ }^{a}$ Metal JSC, ZPZ, 9000 Varna, Bulgaria \\ ${ }^{\mathrm{b}}$ Technical University of Varna, 1 Studentska St., 9010 Varna, Bulgaria \\ * Corresponding author: Tel.: + 710359888606 472.E-mail:d_stavrev@abv.bg
}

\begin{abstract}
The present paper deals with investigation of the possibility for application of laser welding-on technology for repairing the mold cavities of die casting dies. The surface of the samples, made of 32CrMoV12-28 (DIN) steel, was welded on by additional material - maraging alloy with chemical composition $0.02 \mathrm{C}-19.3 \mathrm{Ni}-0.4 \mathrm{~V}-2 \mathrm{Cr}-14.5 \mathrm{Co}-4.7 \mathrm{Mo}-0.25 \mathrm{Al}-0.2 \mathrm{Mn}-0.2 \mathrm{Si}$, (wt \%). The surface treatment was done by pulse laser AL $200 \mathrm{Nd}$ :YAG with a wave length of $1064 \mathrm{~nm}$. To estimate the possibility for additional hardening of the welded-on layers, the samples were heated for 1 hour at temperatures of 450, 500, 550 and $600{ }^{\circ} \mathrm{C}$. The microstructure was investigated by light microscopy, the Vickers microhardness was measured with $100 \mathrm{~g}$ load and XRD-analysis was done. After laser welding-on the hardened surface layer was obtained. Its microstructure possesses dendrite morphology and consists mainly of ferrite oversaturated with alloying elements. The intermetallic compounds of the types $\mathrm{Fe}-\mathrm{Cr}$ and $\mathrm{Fe}-\mathrm{Al}$ are also observed. After ageing $\mathrm{Ni}-\mathrm{Al}$ and Ni-Mo phases precipitate with maximal quantity at a temperature of $550{ }^{\circ} \mathrm{C}$. After ageing at this temperature a maximal hardness of $600-650 \mathrm{HV}$, twice higher than that of the welded-on layer, was observed. The next temperature increase leads to the hardness decrease up to $400-450 \mathrm{HV}$ due to the interruption of the coherent bonds between the phases and transformation of dendrite morphology to equiaxed crystals. As a result of the present investigation the application of the laser welding-on with additional material - maraging alloy, could be recommended for repairing the mold cavities of die casting dies.
\end{abstract}

\section{Keywords}

Intermetallic phases; maraging alloys; laser welding-on; tool steels.

(C) V. Shtarbakov, D. Stavrev, 2016

\section{Introduction}

Maraging (martensitic-aging) alloy mass production and implementation has been rather limited for a long time due to its high cost. These steels are used predominantly in the aircraft and spacecraft industry where they successfully replace titanium alloys [1], mainly in the production of heavy duty gears and shafts in plane engines, rocket engine tanks, satellite sheaths, etc. They are also employed in the manufacturing of precise tool equipment such as squirts, dies and moulds.

The development of new technological methods for material processing, concerning maraging alloy in particular, especially by concentrated energy fluxes (e.g. laser, electron beam, plasma) employed in modern mechanical engineering made it possible for this type of steels to be extensively used in industry. The possibilities for laser [2,3], electron beam [4] or argon arc [5] welding-on of parts are of special interest.

The laser technologies are widely used nowadays for welding-on in repairing many mechanical and tool parts $[6,7]$. Their application is determined by two main factors: treatment of local areas and possibilities for welding-on different materials. The first one enables repairing the defected area with no deformation of the whole detail. The second one gives the possibility for treatment of constructional and tool steels with additional material - maraging steel with required chemical composition according to specific needs. Furthermore, this enables the next heat treatment to be performed according to the application of the repaired parts. It was established [8] that the welding-on of 
Chemical composition of the materials used, wt \%

\begin{tabular}{rccccccccc}
\hline Material & $\mathrm{C}$ & $\mathrm{Si}$ & $\mathrm{Mn}$ & $\mathrm{Cr}$ & $\mathrm{Ni}$ & $\mathrm{V}$ & $\mathrm{Mo}$ & $\mathrm{Co}$ & $\mathrm{Al}$ \\
\hline 32CrMoV12-28 & 0.3 & 0.4 & 0.36 & 3.23 & 0.21 & 0.6 & 2.95 & - & - \\
Marraging alloy & 0.02 & $<0.2$ & $<0.2$ & 2 & 19.3 & 0.4 & 4.7 & 14.5 & 0.25 \\
\hline
\end{tabular}

* S,P $<0.02 \%$; Rest Fe.

\section{Preliminary heat treatment}

\begin{tabular}{ccccc}
\hline Steel & Quenching $T,{ }^{\circ} \mathrm{C}$ & HRC & Tempering $T,{ }^{\circ} \mathrm{C}$ & HRC \\
\hline $32 \mathrm{CrMoV} 12-28$ & $1050^{*}$ & 46 & 650 & 42 \\
\hline
\end{tabular}

*Oil cooling

low-carbon steel $(0.15 \mathrm{C}-0.21 \mathrm{Si}-0.42 \mathrm{Mn}-0.27 \mathrm{Al}$, wt $\%)$ with maraging alloy $(0.04 \mathrm{C}-7.5 \mathrm{Ni}-6.25 \mathrm{Co}-$ $6.25 \mathrm{Mo}-0.6 \mathrm{Ti}-0.1 \mathrm{Al}-3.8 \mathrm{Mn}-1.9 \mathrm{Si}, \mathrm{wt} \%)$ leads to an increase in the welded-on layer hardness from $350-400 \mathrm{HV}_{0.1}$ to $520-560 \mathrm{HV}_{0.1}$ after 8 hours ageing at a temperature of $550{ }^{\circ} \mathrm{C}$. This technology is suitable for repairing especially die casting dies and molds for polymers made of maraging or other tool steels. The other favorable factor is that the temperature ranges of ageing and exploitation coincide which is precondition for improvement of the properties in the course of time. That is why the aim of the present work is to investigate the microstructure and hardness of laser welded-on layers of tool steel with additional material - maraging alloy after ageing.

\section{Experimental methods}

The surface of the samples, made of 32CrMoV12-28 (DIN) steel, was welded on by additional material maraging alloy with chemical composition given in Table 1. All samples were subjected to preliminary heat treatment with regimes shown in Table 2. The surface treatment was done by pulse laser AL $200 \mathrm{Nd}$ :YAG with a $1064 \mathrm{~nm}$ wave length, $200 \mathrm{~W}$ average pulse power with $10 \mathrm{~kW}$ maximal peak and $20 \mathrm{~Hz}$ working frequency. The laser spot diameter on

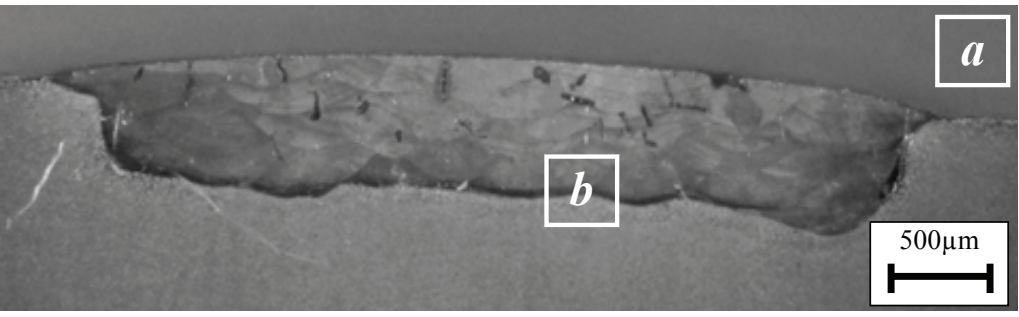

Fig. 1. Cross section $(a)$ and microstructure $(b)$ of the laser welded-on layer: 1 - welded-on zone; 2 - transiton zone; 3 - basic material solution and was studied by light microscopy "Neophot 32". The Vickers microhardness along the hardened layers depth was measured with $100 \mathrm{~g}$ load on "Epitip" microscopy with "Hanemann" appliance. The XRD-analysis was done on "Dron-4C-01" with $\mathrm{Fe}$ anode in $\mathrm{K} \alpha$ emission. Phase analysis was made with the "Line calculate" software.

\section{Results and analysis}

Fig. 1 shows the macrostructure of a welded-on region. The boundaries between the base metal and additional maraging steel as well as the overlapping zones of the layers in filling the welded-on area can be clearly seen. Partial melting and interaction of maraging steel with the base metal is observed only in particular areas of transition zone. There are no defects and cracks due to structural transformations along the boundary between the base and additional metals. In this transition area three zones can be distinguished (Fig. 1 $a$ ).

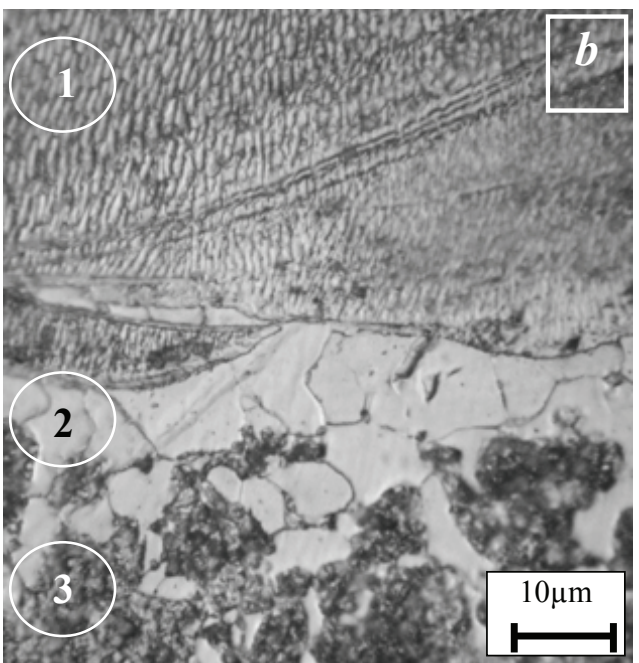


The microstructure of the first of them 1 is characterized with dendrite morphology due to the high speed directed crystallization of additional material during welding-on. Under this zone bright sub-layer with large grain morphology 2 exists as a result of phase transformations in solid state. The phase composition consists mainly of oversaturated ferrite owing to the overheating during welding-on process. The base material 3 with sorbitetroostite microstructure, which does not change during welding-on process, lies under that sub-layer.

The micro-hardness investigations (Fig. 2) show that the hardness of the welded-on layer is in the

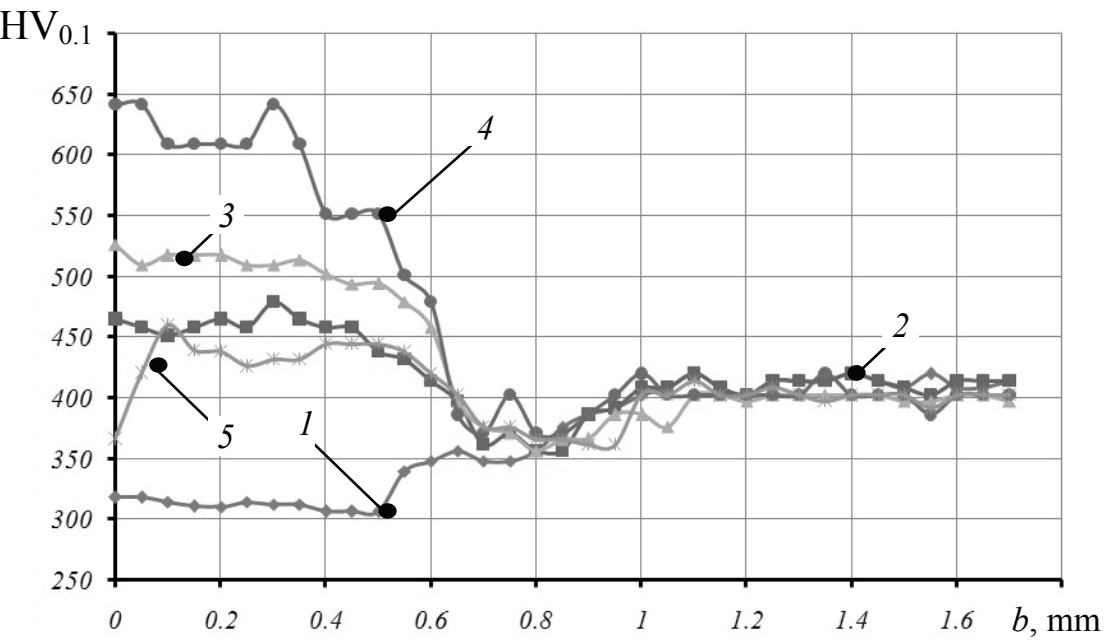

Fig. 2. Micro-hardness changes along the depth of the laser welded-on layer (1) and the laser welded-on layers after ageing at different temperatures: $2-450{ }^{\circ} \mathrm{C} ; 3-500{ }^{\circ} \mathrm{C} ; 4-550{ }^{\circ} \mathrm{C} ; 5-600{ }^{\circ} \mathrm{C}$ range $300-320 \mathrm{HV}$. The micro-hardness distribution corresponds to the microstructure of the maraging steel weldment shown in Fig. $3 a$. The microstructure consists of low-carbon, high alloyed with $\mathrm{Ni}$, Co and Mo package martensite in dendrites and austenite sublayer along their boundaries. Probably this high-alloyed martensite possesses high dislocation density which is precondition for precipitation of intermetallic compounds of the $\mathrm{Ni}_{3} \mathrm{Mo}$ type $[7,8]$ during the following ageing. The micro-

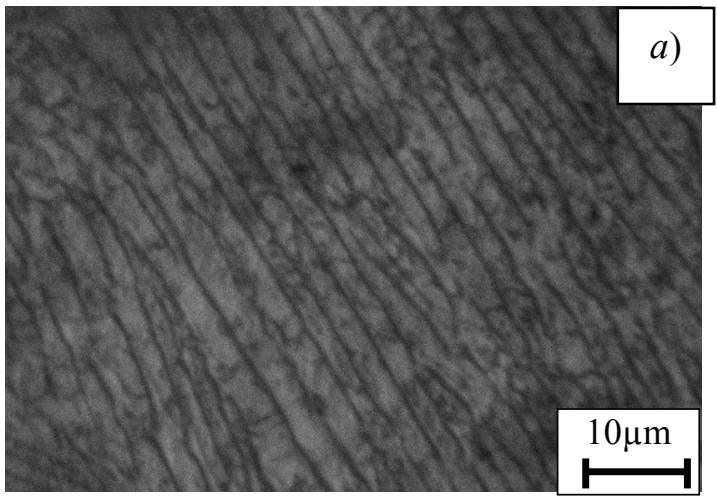

hardness investigations after ageing in the temperature range $450-600{ }^{\circ} \mathrm{C}$ (Fig. 2) verify our hypothesis. After $1 \mathrm{~h}$ ageing at a temperature of $550{ }^{\circ} \mathrm{C}$, the hardness increases up to $600-640 \mathrm{HV}$. It completely corresponds to the temperature range of ageing of the maraging steel investigated for obtaining the maximal hardness. The microstructure of the welded-on layer (Fig. $3 a, b, c$ ) retains its clearly distinguished dendrite morphology after ageing in the temperature
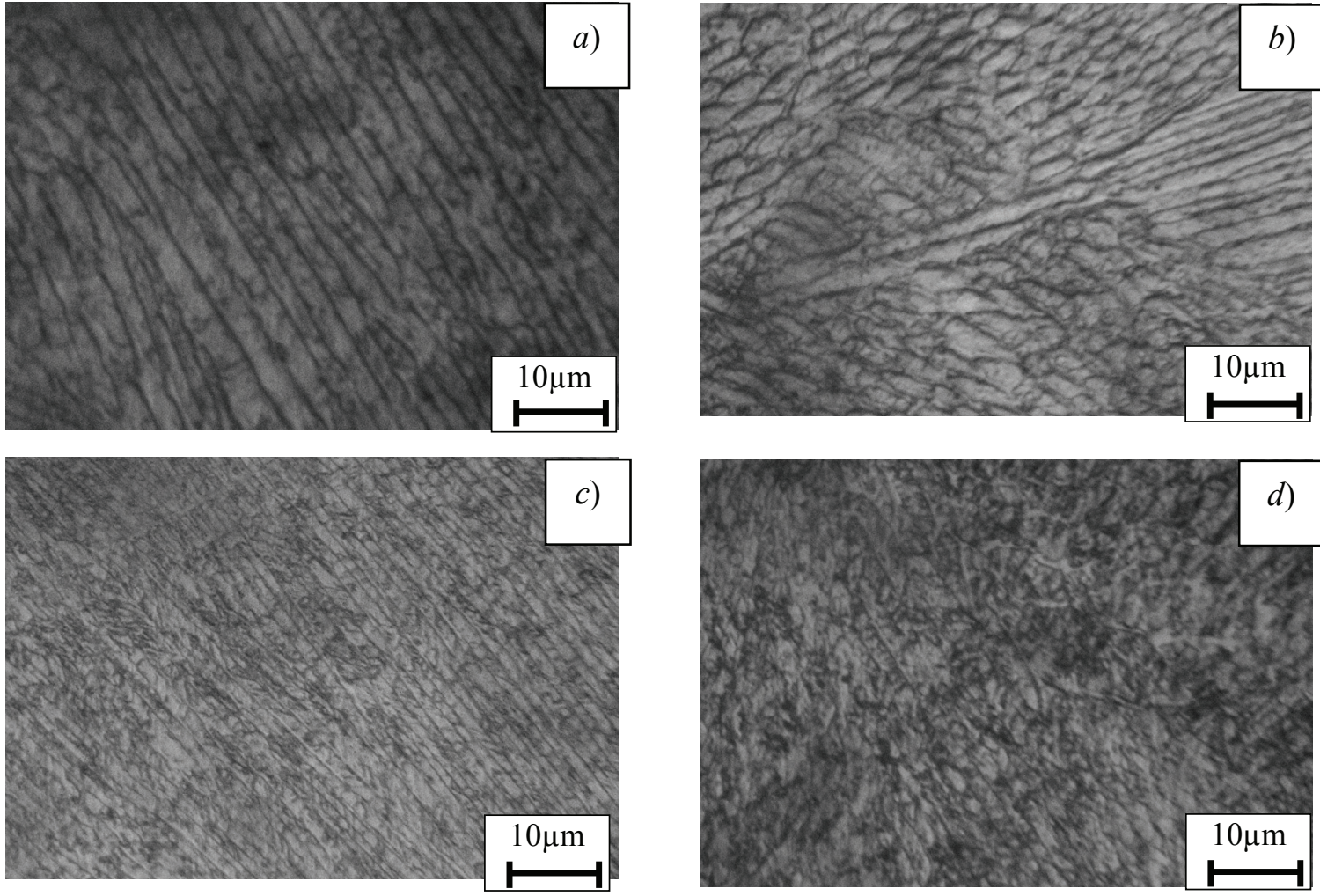

Fig. 3. Microstructure of a welded-on layer $(a)$ and welded-on layers after ageing at different temperatures: $b-500{ }^{\circ} \mathrm{C} ; c-550{ }^{\circ} \mathrm{C} ; d-600{ }^{\circ} \mathrm{C}$ 

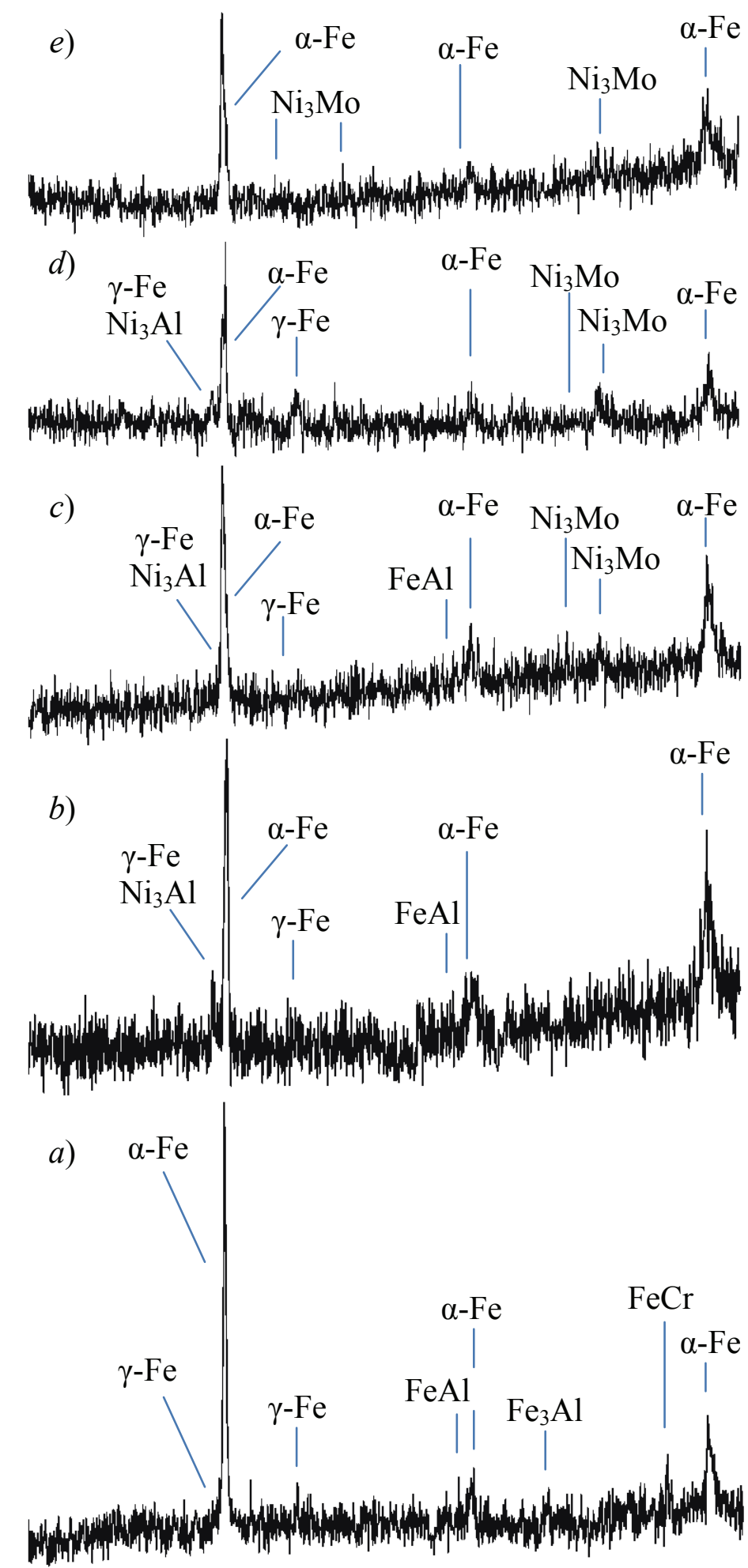

$\begin{array}{lllllllllllllllll}35 & 40 & 45 & 50 & 55 & 60 & 65 & 70 & 75 & 80 & 85 & 90 & 95 & 100 & 105 & 110 & 2 \theta\end{array}$

\footnotetext{
Fig. 4. XRD analysis of welded-on layer (a) and welded-on layers after ageing at different temperatures:

$b-450{ }^{\circ} \mathrm{C} ; c-500{ }^{\circ} \mathrm{C} ; d-550{ }^{\circ} \mathrm{C} ; e-600{ }^{\circ} \mathrm{C}$
}

range $450-550{ }^{\circ} \mathrm{C}$. After ageing at the highest temperature of $600{ }^{\circ} \mathrm{C}$ (Fig. $3 d$ ) the coagulation of intermetallic phases is observed as the process is most clearly pronounced in the austenite sub-layer along the dendrite boundaries. That sub-layer probably is enriched with the alloying elements $\mathrm{Ni}, \mathrm{Co}$ and Mo of the additional material due to the liquation during the high speed crystallization. As a result, the intermetallic compounds precipitate and coagulate during ageing, leading to formation of equiaxed crystals and elimination of dendrite morphology.

Fig. 4 shows data of XRD analysis of welded-on layer and layers after ageing in the temperature range $450-600{ }^{\circ} \mathrm{C}$. The phase composition of welded-on layer consists mainly of oversaturated ferrite and austenite. The intermetallic compounds of $\mathrm{Fe}$ and $\mathrm{Al}$ $\left(\mathrm{FeAl}\right.$ and $\left.\mathrm{Fe}_{3} \mathrm{Al}\right)$ as well as of $\mathrm{Fe}$ and $\mathrm{Cr}$ (FeCr) (Fig. $4 a$ ) can be also observed. After ageing at a temperature of $450{ }^{\circ} \mathrm{C}$ the compounds of the $\mathrm{Ni}_{3} \mathrm{Al}$ types (Fig. $4 \mathrm{~b}$ ) begin to precipitate in the microstructure of the layer leading to hardness increase up to about $450 \mathrm{HV}$. The following ageing temperature increase up to $500{ }^{\circ} \mathrm{C}$ leads again to the hardness increase up to about $500 \mathrm{HV}$ but new phases were not identified (Fig. $4 c$ ). The maximal hardness $600-650 \mathrm{HV}$ of the welded-on layer was observed after ageing at a temperature of $550{ }^{\circ} \mathrm{C}$ where the new intermetallic compounds $\mathrm{Ni}_{3} \mathrm{Mo}$ and NiMo were precipitated (Fig. $4 d$ ). The hardening effect in the temperature range $450-550^{\circ} \mathrm{C}$ is probably due to the new precipitated intermetallic compounds and their coherent bonds with the main phases of the microstructure.

After ageing at a temperature of $600{ }^{\circ} \mathrm{C}$ the new intermetallic compound NiMo is identified in the microstructure of the weldedon layer (Fig. $4 e$ ), but the hardness decreases up to $400-450 \mathrm{HV}$ (Fig. 2). This is most probably due to the interruption of the coherent bonds and formation of separate intermetallic compounds of the type $\mathrm{Fe}-\mathrm{Al}$, $\mathrm{Ni}-\mathrm{Al}$ and most of all Ni-Mo. The above mentioned process is accompanied with elimination of the dendrite morphology of the laser welded-on layer and formation of equiaxed crystals.

It should be noted that the availability of intermetallic phases NiMo, NiAl, FeAl determined by XRD analysis is supposed. 
The present results give direction for future studies and determination of the exact stoichiometric composition of the discussed intermetallic phases by using of EDS analysis.

\section{Conclusion}

After laser welding-on the $32 \mathrm{CrMoV} 12-28$ (DIN) steel with additional material - maraging alloy with chemical composition $0.02 \mathrm{C}-19.3 \mathrm{Ni}-0.4 \mathrm{~V}-2 \mathrm{Cr}-$ $14.5 \mathrm{Co}-4.7 \mathrm{Mo}-0.25 \mathrm{Al}-0.2 \mathrm{Mn}-0.2 \mathrm{Si}, \quad$ (wt \%) the hardened surface layer was obtained. Its microstructure possesses dendrite morphology and consists mainly of ferrite oversaturated with alloying elements. The intermetallic compounds of the types $\mathrm{Fe}-\mathrm{Cr}$ and $\mathrm{Fe}-\mathrm{Al}$ are also observed.

After ageing $\mathrm{Ni}-\mathrm{Al}$ and $\mathrm{Ni}-\mathrm{Mo}$ phases precipitate with maximal quantity at a temperature of $550^{\circ} \mathrm{C}$. After ageing at this temperature the maximal hardness 600-650 HV, twice higher than that of the welded-on layer, was observed. The next temperature increase leads to the hardness decrease up to $400-450 \mathrm{HV}$ due to the interruption of the coherent bonds between the phases and transformation of dendrite morphology to equiaxed crystals.

As a result of the present investigation the application of the laser welding-on with additional material - maraging alloy could be recommended for repairing the mold cavities of die casting dies. The microstructure transformations after ageing at temperatures, coinciding in many cases with exploitation temperatures, are favorable and can lead to optimal die behavior during production.

\section{References}

1. Novotny, P.M. \& Maurer G.E. (2007) Ultrahigh-strength steels vs. Titanium alloys, Advanced Materials \& Processes, 165 (11), 37-40.

2. Yilbas, B.S., Momin, O. \& Shuja S.Z. (2012) Laser heating of titanium and steel: Phase change at the surface, International Journal of Thermal Science, (54), 230-241.

3. Yilbas, B.S., Shuja, S.Z. \& Khan, S.M.A. (2011) Laser repetitive pulse heating of tool surface, Optics \& Laser Technology, 43 (4), 754-761.

4. Ramana, P.V. et al. (2010) Microstructure and residual stress distribution of similar and dissimilar electron beam welds - Maraging steel to medium alloy medium carbon steel, Materials \& Design, 31(2), 749-760.

5. Shamantha, C.R. et al. (2000) Microstructural changes during welding and subsequent heat treatment of $18 \mathrm{Ni}$ (250-grade) maraging steel, Material Science \& Engineering, 287 (1), 43-51.

6. Grum, J. \& Slabe, J.M. (2006) Effect of laserremelting of surface cracks on microstructure and residual stresses in $12 \mathrm{Ni}$ maraging steel, Applied Surface Science, 252 (13), 4486-4492.

7. Grum, J. \& Slabe, J.M. (2005) Nanoscale evaluation of laser-based surface treated $12 \mathrm{Ni}$ maraging steel, Applied Surface Science, 247 (1-4), 458-465.

8. Grum, J. \& Slabe, J.M. (2003) A comparison of tool-repair methods using $\mathrm{CO}_{2}$ laser surfacing and arc surfacing, Applied Surface Science, (208-209), 424-431. 